\title{
Depression, Anxiety and Stress among Female College Students in Delhi having Normal and Disordered Eating Behaviours
}

\author{
Shipra Gupta', Deeksha Kapur
}

${ }^{1}$ Assistant Professor, Department of Food and Nutrition, Institute of Home Economics, University of Delhi, Delhi, India. ${ }^{2}$ Professor, School of Continuing Education, Indira Gandhi National Open University, New Delhi, India.

DOI: https://doi.org/10.24321/2349.2880.201820

\section{Abstract}

Background: Disordered eating behaviour is an emerging problem among young Indian females who undergo multiple changes during early adulthood. It may pose serious health consequences for these young women in their reproductive age. Psychological factors such as depression, anxiety and stress are likely to influence the eating practices of young females and predispose them to disordered eating behaviour.

Objectives: The study was conducted to determine the prevalence and severity of depression, anxiety and stress among female college students in Delhi having normal and disordered eating behaviours.

Materials and Methods: A total of 734 female undergraduate college students from University of Delhi comprised the study sample. An adapted Eating Attitudes Test (EAT)-26 was used to identify subjects having disordered eating behaviour and Depression Anxiety Stress Scale (DASS)-21 was used to assess the occurrence and severity of depression, anxiety and stress among them.

Results: Findings revealed that prevalence of depression, anxiety and stress, ranging from mild to extremely severe forms, among the subjects was $46.6 \%, 63.8 \%$ and $43.1 \%$ respectively. Scores on stress, anxiety and depression subscales for subjects having disordered eating behaviour were significantly higher than those having normal eating behaviour and with regard to severity of depression, anxiety and stress, significant differences were found between the subjects. Significant positive correlations between EAT-26 scores of subjects and their scores on depression, anxiety and stress subscales were also found.

Conclusion: The study indicated that prevalence of depression, anxiety and stress was substantial among the female college students in Delhi and played an important role in the occurrence of disordered eating behaviour among them. Suitable interventions for alleviating depression, anxiety and stress among young females need to be promoted to prevent disordered eating behaviour among them.

Keywords: Anxiety, Depression, Disordered eating behaviour, Female college students, Stress

\section{Introduction}

In recent years, disordered eating behaviour has been on a rise in the Asian part of the world due to rapid industrialization and urbanization. ${ }^{1}$ This behaviour includes a wide range of eating related problems, such as maladaptive behaviour related to dissatisfaction with body shape or size, and inadequate eating behaviour, such as purging, binge eating and restricting diet to lose or control weight. ${ }^{2-4} \mathrm{At}$ the same time as increasing disordered behaviour, prevalence of mental disorders that refer to a range of anxiety and depressive disorders, has also been increasing all over the world. It is estimated that $4.4 \%$ and $3.6 \%$ of the world's population suffers from depressive and anxiety disorders respectively and these problems are more

Corresponding Author: Ms. Shipra Gupta, Department of Food and Nutrition, Institute of Home Economics, University of Delhi, Delhi, India.

E-mail Id: shipra.gupta@ihe.du.ac.in

Orcid Id: https://orcid.org/0000-0003-2413-2254

How to cite this article: Gupta S, Kapur D. Depression, Anxiety and Stress among Female College Students in Delhi having Normal and Disordered Eating Behaviours. Ind J Youth Adol Health 2018; 5(4): 1-5. 
common among females than males. Moreover, a range of severity of these problems is seen, with at least one third of the symptomatic cases following a moderate to severe course. ${ }^{5}$ India too has been witnessing a surge in these common mental health problems in the last few years. According to the World Health Organization, prevalence of depressive and anxiety disorders among the Indians is quite close to the global averages, i.e. $4.5 \%$ and $3.0 \%$ respectively. ${ }^{5}$ Researchers have projected depression, anxiety and stress as the most prevalent mental health issues among the undergraduate students. ${ }^{6}$ Young adults are particularly at risk of these problems due to several changes taking place in their lives due to the transition from protected home and school environments to college and professional lives. ${ }^{7,8}$ These changes exert different types and grades of pressure on them, some of which they are unable to cope with effectively and fall prey to health issues such as depression, anxiety and stress. ${ }^{9}$ Moreover, studies have shown that depression, anxiety and stress share an interdependent relationship and influence each other. ${ }^{10-12}$

These mental health problems are likely to further predispose young adults, especially females, to disordered eating behaviour and such behaviour among young women increases their risk to serious health and nutritional consequences in their reproductive age.

In the present study, an attempt was made to determine the prevalence and severity of depression, anxiety and stress among female college students in Delhi having normal and disordered eating behaviours.

\section{Materials and Methods}

A cross-sectional descriptive study was carried out in different women's colleges in the University of Delhi. Sample size was calculated as 646 and assuming a nonresponse rate of $30 \%$, a total of about 840 female college students were enrolled to participate in the study using multistage sampling technique. The students were between 18-21 years, never-married and willing to participate and extend their cooperation during the entire course of study. Students suffering from any genetic/ chronic diseases and disorders were not included in the study. Written informed consent was obtained from the students who agreed to participate in the study. A total of 734 students from colleges in different districts of Delhi comprised the final study sample.

An interview-cum-questionnaire schedule was designed in bilingual format to gather information about the personal and family profile of subjects. An adapted and validated bilingual Eating Attitudes Test (EAT-26) was used for identifying disordered eating behaviour among the subjects and classifying them as those having normal and disordered eating behaviours. EAT-26 is a self-report inventory consisting of 26 items that are rated on a 6-point Likert scale. Cut off score of 20 on this tool has been suggested to identify individuals with problematic attitude and behaviour towards eating; i.e. disordered eating behaviour. ${ }^{13}$

An adapted and validated bilingual Depression Anxiety Stress Scale-21 (DASS-21) was used for determining the occurrence and severity of these conditions among the subjects. DASS consists of three subscales that measure the negative emotional states of depression, anxiety and stress. ${ }^{11}$ Each subscale includes 7 items that respondents' rate on a 4-point scale. Scores on each subscale of depression, anxiety and stress are summed up separately and multiplied by 2 to make them comparable to the DASS normative data scores. The possible scores on each of these subscales range from 0-42.

Appropriate statistical analysis of the obtained data was carried out using Statistical Package for Social Sciences (SPSS) version 21.0 developed by IBM Corporation. Frequency and percentages were calculated for personal and family profile characteristics of the subjects. The percentage prevalence and severity of depression, anxiety and stress were also calculated. Mean, standard deviation (SD), median and interquartile range (IQR) were calculated for scores obtained by the subjects on depression, anxiety and stress subscales. Mann-Whitney $U$ test and Chi square test were used to determine statistically significant differences in the scores and severity of depression, anxiety and stress respectively among subjects exhibiting normal and disordered eating behaviours. Spearman's correlation coefficient was calculated to assess the association of EAT-26 scores with depression, anxiety and stress scores obtained by the subjects. A p-value less than or equal to 0.05 was considered statistically significant.

\section{Results}

Data on personal and family profile of the subjects revealed that the mean age of subjects in the present study was $19.26 \pm 0.99$ years. Nearly $70 \%$ of them had been living in the National Capital Region of India since their birth. Maximum subjects (64.4\%) belonged to nuclear families and majority of them (84.2\%) lived with their families at home. About $77 \%$ of the subjects belonged to families of upper and upper middle socioeconomic status.

Table 1.Prevalence of depression, anxiety and stress among subjects $(n=734)$

\begin{tabular}{|c|c|c|}
\hline Problem & Number of subjects & Prevalence (\%) \\
\hline Depression & 342 & 46.6 \\
\hline Anxiety & 468 & 63.8 \\
\hline Stress & 316 & 43.1 \\
\hline
\end{tabular}

Table 1 shows that more than $40 \%$ subjects each exhibited mild to extremely severe forms of depression and stress; while prevalence of different grades of anxiety was observed among nearly $64 \%$ of the subjects and was highest among the three mental health issues that were determined in the sample. 
Subjects in the present study were categorized as having normal eating behaviour (NEB) and disordered eating behaviour (DEB) based on the cut off score of 20 obtained by them on EAT-26 tool. It was found that the scores on depression, anxiety and stress subscales of DASS-21 among NEB and DEB subjects were significantly different. There was also a wide variation in the range of scores obtained on these scales by subjects from NEB and DEB groups. It was further observed that the scores of subjects on stress subscale were higher than the scores obtained by them on anxiety and depression subscales, which were similar to each other (Table 2).
Based on severity of depression, it was found that higher percentages of subjects from DEB group exhibited moderate to extremely severe forms of depression (Table 3 ). In case of anxiety, higher percentages of subjects from DEB group had severe to extremely severe forms of anxiety as compared to subjects from NEB group (Table 4).

As depicted in Table 5, findings about severity of stress revealed that more than half the total sample displayed normal levels of stress. Higher percentages of subjects in DEB group exhibited different levels of severity of stress, ranging from mild to extremely severe, as compared to NEB group subjects.

Table 2.Scores for depression, anxiety and stress on DASS-21

\begin{tabular}{|c|c|c|c|c|c|c|c|}
\hline \multirow[t]{2}{*}{ Parameter } & \multicolumn{2}{|c|}{ NEB group $(n=591)$} & \multicolumn{2}{|c|}{ DEB group ( $n=143)$} & \multirow[t]{2}{*}{ p-value } & \multicolumn{2}{|c|}{ Total $(n=734)$} \\
\hline & Mean (SD) & Median (IQR) & Mean (SD) & Median (IQR) & & Mean (SD) & Median (IQR) \\
\hline Depression & $9.57(8.02)$ & $\begin{array}{c}8.00 \\
(4.00-14.00)\end{array}$ & $\begin{array}{l}13.62 \\
(9.88)\end{array}$ & $\begin{array}{c}12.00 \\
(6.00-20.00)\end{array}$ & $<0.001^{*}$ & $\begin{array}{l}10.36 \\
(8.56)\end{array}$ & $\begin{array}{c}8.00 \\
(4.00-14.00)\end{array}$ \\
\hline Anxiety & $9.92(7.04)$ & $\begin{array}{c}8.00 \\
(4.00-14.00)\end{array}$ & $\begin{array}{l}13.64 \\
(8.50)\end{array}$ & $\begin{array}{c}12.00 \\
(6.00-20.00)\end{array}$ & $<0.001^{*}$ & $\begin{array}{l}10.64 \\
(7.49)\end{array}$ & $\begin{array}{c}10.00 \\
(4.00-16.00)\end{array}$ \\
\hline Stress & $14.00(8.19)$ & $\begin{array}{c}14.00 \\
(8.00-20.00)\end{array}$ & $\begin{array}{l}18.82 \\
(9.46)\end{array}$ & $\begin{array}{c}18.00 \\
(12.00-26.00)\end{array}$ & $<0.001^{*}$ & $\begin{array}{l}14.94 \\
(8.66)\end{array}$ & $\begin{array}{c}14.00 \\
(8.00-20.00)\end{array}$ \\
\hline
\end{tabular}

*Mann-Whitney U test; NEB-Normal Eating Behaviour, DEB-Disordered Eating Behaviour; SD-Standard Deviation, IQR-Interquartile Range

Table 3.Distribution of subjects according to severity of depression

\begin{tabular}{|c|c|c|c|c|c|}
\hline Depression Categories & Score & NEB group $(n=591)$ & DEB group $(n=143)$ & p-value & Total $(n=734)$ \\
\hline Normal & $0-9$ & $330(55.8)$ & $62(43.4)$ & \multirow[t]{5}{*}{$<0.001^{*}$} & $392(53.4)$ \\
\hline Mild & $10-13$ & $111(18.8)$ & $13(9.1)$ & & 124 (16.9) \\
\hline Moderate & $14-20$ & 94 (15.9) & $33(23.1)$ & & $127(17.3)$ \\
\hline Severe & $21-27$ & $31(5.2)$ & $18(12.6)$ & & $49(6.7)$ \\
\hline Extremely severe & $28+$ & $25(4.2)$ & 17 (11.9) & & $42(5.7)$ \\
\hline
\end{tabular}

Figures in parentheses denote percentages, ${ }^{*} \chi^{2}$ test; NEB-Normal Eating Behaviour, DEB-Disordered Eating Behaviour

Table 4.Distribution of subjects according to severity of anxiety

\begin{tabular}{|c|c|c|c|c|c|}
\hline Anxiety Categories & Score & NEB group $(\mathrm{n}=591)$ & DEB group $(\mathrm{n}=143)$ & $\mathrm{p}$-value & Total $(\mathrm{n}=734)$ \\
\hline Normal & $0-7$ & $229(38.7)$ & $37(25.9)$ & $<0.001^{*}$ & $266(36.2)$ \\
\hline Mild & $8-9$ & $77(13.0)$ & $10(7.0)$ & & $87(11.9)$ \\
\cline { 1 - 4 } Moderate & $10-14$ & $164(27.7)$ & $33(23.1)$ & & $197(26.8)$ \\
\hline Severe & $15-19$ & $56(9.5)$ & $25(17.5)$ & & $81(11.0)$ \\
\hline Extremely severe & $20+$ & $65(11.0)$ & $38(26.6)$ & & $103(14.0)$ \\
\hline
\end{tabular}

Figures in parentheses denote percentages, * $\chi^{2}$ test; NEB-Normal Eating Behaviour, DEB-Disordered Eating Behaviour

Table 5.Distribution of subjects according to severity of stress

\begin{tabular}{|c|c|c|c|c|c|}
\hline Stress Categories & Score & NEB group $(n=591)$ & DEB group $(n=143)$ & p-value & Total $(n=734)$ \\
\hline Normal & $0-14$ & $362(61.3)$ & $56(39.2)$ & \multirow[t]{5}{*}{$<0.001^{*}$} & $418(56.9)$ \\
\hline Mild & $15-18$ & $78(13.2)$ & $20(14.0)$ & & $98(13.4)$ \\
\hline Moderate & $19-25$ & $87(14.7)$ & $30(21.0)$ & & $117(15.9)$ \\
\hline Severe & $26-33$ & $50(8.5)$ & 27 (18.9) & & $77(10.5)$ \\
\hline Extremely severe & $34+$ & $14(2.4)$ & $10(7.0)$ & & $24(3.3)$ \\
\hline
\end{tabular}

Figures in parentheses denote percentages, * $\chi^{2}$ test; NEB-Normal Eating Behaviour, DEB-Disordered Eating Behaviour 
Statistically significant positive correlations were found between EAT-26 score and depression, anxiety and stress scores of the subjects. It was observed that EAT-26 scores of the subjects increased with increase in their depression, anxiety and stress scores (Table 6).

Table 6.Association of EAT-26 scores with depression, anxiety and stress scores of subjects

\begin{tabular}{|l|c|c|}
\hline & $\rho^{*}$ & $p$-value \\
\hline $\begin{array}{l}\text { EAT-26 scores versus depression } \\
\text { scores }\end{array}$ & 0.229 & $<0.001$ \\
\hline EAT-26 scores versus anxiety scores & 0.224 & $<0.001$ \\
\hline EAT-26 scores versus stress scores & 0.277 & $<0.001$ \\
\hline
\end{tabular}

*Spearman's correlation coefficient

\section{Discussion}

As rapid increase in mental health issues such as depression, anxiety and stress may have an adverse influence on the eating behaviour of young female students and predispose them to clinical eating disorders, it was considered important to assess their prevalence among female college students in Delhi who exhibited normal and disordered eating behaviours.

Prevalence of anxiety among subjects in our study was found to be the highest while depression and stress were observed among a similar and substantial percentage of subjects. Mutalik NR et al. ${ }^{14}$ also reported that prevalence of anxiety was highest among college-going females in Bagalkot, Karnataka, i.e. $86.5 \%$, while depression and stress were observed among comparatively fewer subjects (78.4\% and 64.9\% respectively). A study on students from Punjab University, Chandigarh, reported that 76.4\%, 75.1\% and $81.5 \%$ females exhibited depression, anxiety and stress respectively. ${ }^{15}$ These studies reported much higher prevalence of mental health issues as compared to the findings in our study. In a study in Delhi among both male and female medical students, depression, anxiety and stress were observed among $32.0 \%, 40.1 \%$ and $43.8 \%$ subjects respectively. ${ }^{16}$ There are several studies from India and other parts of the world that have looked into the prevalence of mental health issues among undergraduate students enrolled in specific professional courses, such as medicine and nursing; ${ }^{16-19}$ however, only a limited number of studies till date have assessed the prevalence of mental health issues among undergraduate students enrolled in non-professional courses where the influencing factors and situation of these conditions might be different from students enrolled in professional courses. Moreover, these studies have also not assessed depression, anxiety and stress among students having normal and disordered eating behaviours.

Higher scores on depression, anxiety and stress scales were obtained by subjects having disordered eating behaviour as compared to those having normal eating behaviour in our study. Chellappa AR and Karunanidhi $\mathrm{S}^{20}$ also reported higher scores on depression and anxiety for female college students in Chennai having disordered eating behaviour in comparison to those having normal eating behaviour. They speculated that students who were depressed were more likely to either overeat or starve themselves, and the resultant body appearance and physique may further aggravate depression leading to a vicious cycle of disordered eating and depression. Also, higher anxiety levels may lead to snacking in between meals, skipping meals or binge eating as means to cope with their anxiety and gradually all these unhealthy eating habits may lead to clinical forms of eating disorders. Studies from other parts of the world have also reported that scores on depression, anxiety and stress were higher in undergraduate students exhibiting disordered eating behaviour. ${ }^{21,22}$

Prevalence of severe and extremely severe forms of anxiety among the females exhibiting disordered eating behaviour were much higher in our study sample (44.1\%) as compared to these forms of depression (24.5\%) and stress (25.9\%). Anxiety, seemingly is a much bigger problem than depression and stress among young female students as most of them are conscious about their appearance and social relationships; and the constant pressure to look good, be socially accepted and perform well academically tends to make them worry all the time..$^{23,25}$

Depression, anxiety and stress were found to be significantly positively correlated with disordered eating behaviour in our study. Consistent with our findings, a study on Malaysian university students by Gan WY et al. ${ }^{26}$ reported significant positive correlations between disordered eating and depression, anxiety and stress. A study on Indian medical students also reported a significant positive correlation between disordered eating and anxiety. ${ }^{27}$

\section{Conclusion}

The prevalence of depression, anxiety and stress among female college students in Delhi was found to be substantial, and severe forms of these problems were observed more in students who exhibited disordered eating behaviour. It is generally believed that mental health issues result in either increased or decreased intake of food and following unhealthy eating patterns, mainly as coping strategies for these problems. The present study provides evidence about the linkages between disordered eating behaviour and depression, anxiety and stress among female college students in Delhi who were enrolled in non-professional courses. The study also establishes the urgent need to promote suitable interventions for alleviating depression, anxiety and stress among young females in order to prevent disordered eating behaviour and its ill-effects among them.

\section{Acknowledgement}

The authors are grateful to the college personnel and students who supported and actively participated in the study to provide valuable information. 


\section{Conflict of Interest: None}

\section{References}

1. Pike KM, Dunne PE. The rise of eating disorders in Asia: a review. J Eat Disord 2015; 3: 33.

2. American Dietetic Association. Position of the American Dietetic Association: nutrition intervention in the treatment of anorexia nervosa, bulimia nervosa, and other eating disorders. J Am Diet Assoc 2006; 106: 2073-82.

3. Sischo L, Taylor J, Martin PY. Carrying the weight of self-derogation? Disordered eating practices as social deviance in young adults. Deviant Behav 2006; 27: 1-30.

4. Kelly SD, Howe CJ, Hendler JP et al. Disordered eating behaviors in youth with type 1 diabetes. Diabetes Educ 2005; 34: 572-83.

5. Depression and other common mental disorders: global health estimates. World Health Organization, Geneva. 2017.

6. Aldiabat KM, Matani NA, Navenec NCL. Mental health among undergraduate university students: A background paper for administrators, educators and healthcare providers. Univers J Public Health 2014; 2(8): 209-14.

7. Verger $\mathrm{P}$, Combes JB, Kovess-Masfety $\mathrm{V}$ et al. Psychological distress in first year university students: Socioeconomic and academic stressors, mastery and social support in young men and women. Soc Psychiatry Psychiatr Epidemiol 2009; 44(8): 643-50.

8. Hicks $\mathrm{T}$, Heastie $\mathrm{S}$. High school to college transition: A profile of the stressors, physical and psychological health issues that affect the first-year on-campus college student. J Cult Divers 2008; 15: 143-7.

9. Talwar P, Tan KW, Kartini AG et al. The goodness-offit of DASS-21 models among University Students. Malaysian J Public Health Med 2016; 16(3): 219-26.

10. Kessler RC, Chiu WT, Demler O et al. Prevalence, severity, and comorbidity of 12-month DSM-IV disorders in the National Comorbidity Survey Replication. Arch Gen Psychiat 2005; 62: 617-709.

11. Lovibond SH, Lovibond PF. Manual for the Depression Anxiety Stress Scales. $2^{\text {nd }} E d$. Sydney, Psychology Foundation, 1995.

12. Hammen C. Generation of stress in the course of unipolar depression. J Abnorm Psychol 1991; 100: 555-61.

13. Garner DM, Olmsted MP, Bohr $Y$ et al. The eating attitudes test: Psychometric features and clinical correlates. Psychol Med 1982; 12: 871-8.

14. Mutalik NR, Moni S, Choudhari SB et al. Depression, anxiety, stress among college students in Bagalkot: $\mathrm{A}$ college-based study. Int J Indian Psychol 2016; 3(4): 68.

15. Singh M, Goel NK, Sharma MK et al. Prevalence of depression, anxiety and stress among students of Punjab University, Chandigarh. Nat/ J Community Med 2017; 8(11): 666-71.
16. Taneja N, Sachdeva S, Dwivedi N. Assessment of depression, anxiety, and stress among medical students enrolled in a medical college of New Delhi, India. Indian J Soc Psychiatry 2018; 34: 157-62.

17. Wahed WYA, Hassan SK. Prevalence and associated factors of stress, anxiety and depression among medical Fayoum University students. Alexandria J Med 2017; 53: 77-84.

18. Cheung T, Wong SY, Wong KY et al. Depression, anxiety and symptoms of stress among Baccalaureate nursing students in Hong Kong: A cross-sectional study. Int J Environ Res Public Health 2016; 13: 779.

19. Iqbal S, Gupta S, Venkatarao E. Stress, anxiety and depression among medical undergraduate students and their socio-demographic correlates. Indian J Med Res 2015; 141(3): 354-7.

20. Chellappa AR, Karunanidhi S. Eating attitudes and its psychological correlates among female college students. Global J Human Social Sci: Arts and Humanities 2013; 13.

21. Chang $W$, Nie $M$, Kang $Y$ et al. Subclinical eating disorders in female medical students in Anhui, China: a cross-sectional study. Nutr Hosp 2015; 31(4): 1771-7.

22. Fragkos KC, Frangos CC. Assessing eating disorder risk: The pivotal role of achievement anxiety, depression and female gender in non-clinical samples. Nutrients 2013; 5: 811-28.

23. Gitimu PN, Jameson MM, Turel T et al. Appearance issues, depression, and disordered eating among college females. Cogent Psychology 2016; 3(1): 1196512.

24. Sharma P, Kirmani MN. Exploring depression and anxiety among college going students. Int J Sci Res 2015; 4(6): 528-32.

25. Ahmad R, Bano Z, Riaz Z et al. Social anxiety as a predictor of adjustment problems in female students during adolescence. Bahria J Professional Psychol 2014; 13(1): 6-24.

26. Gan WY, Mohd T, Mohd N et al. Disordered eating behaviors, depression, anxiety and stress among Malaysian University students. College Stud I 2011; 45 (2): 296-309.

27. Panchami, Samuel T. A cross-sectional study of disturbed eating attitudes and behaviours in medical students. Int J Res Med Sci 2016; 4(7): 2830-3.

Date of Submission: 2018-09-29 Date of Acceptance: 2018-10-08 